The first of these papers was held over from the last issue of the Clean Air Journal. The second paper was presented at a recent meeting.

\title{
SOME INFLUENCES ON POWER STATION CEIMNEY PLUMES
}

\section{J.F. HUMPHREYS}

\section{SUTMIARY}

The behaviour of a plume as it leaves a chimney and progresses into the atmosphere is discussed. It is shown that the plume is subject to numerous influences but careful chimney design can eliminate some effects and make adequate allowance for others.

\section{INTRODUCTION}

The use of pulverised coal in the generation of electricity inevitably means that considerable quantities of dust and sulphur dioxide are produced which need to be disposed of harmlessly and without nuisance. In comron with other utilities throughout the world, the method of control employed by ESCOM is to firstly reduce the dust burden using electrostatic precipitators and ther to emit the residual dust together with the sulphur dioxide and the other combustion gases to atmosphere from tall stacks. The significance of the plume thus formed depends on its basic composition and on how well the undesirable constituents are diluted by the atmosphere before reaching ground level. The composition of the coal and plant operation control the first factor whilst the second is determined by meteorological conditions and other external effects. It is the latter category which is given consideration in the present paper.

The basic requirement of a plume is that it should progress upwards as it leaves the chimney and not immediately start on a downward path to ground. The greater the plume rise the lower is the pollution concentration at ground level and the latter can be calculated knowing the height to which the plume rises. The potential for the plume to rise derives largely from 
its thermal buoyancy and the rise car substantially increase the effective height of the chimney as shown in Figure (1). In these circumstances the source of emission is effectively at a position much higher than the chimney mouth and this is very helpful in reducing ground level concentrations of pollutants. However, this desirable plume behaviour is very sensitive to a number of external effects which by careful chimney design need to be avoided or otherwise catered for. Some of the extermal influences on the plume and their recognition in chimney design will be discussed.

\section{DOWNLRAUGHT}

A first significant consideration affecting plume behaviour is the layout and dimensions of the station buildirgs with respect to the chimney. This is because the buildings disturb the airflow patterns by their presence. A general indication of what happens is shown in Figure (2) which is a typical side view of a power station. Vortices are shed by the various structures causing a downdraught and if the chimney is not sufficiently high the smoke may be caught in these downward sweeping currents and be swept to ground before having time to dilute sufficiently. It has been found that this effect can be avoided by making the chimney at least $2 \frac{1}{2}$ times as high as the tallest immediately adjacent structure, which is the boiler house, and this policy has been adopted by ESCOM for its modern stations. A comparison between old and new stations is shown in Table 1. Moreover, the pattern and severity of vortices shed by a building are such that it is best to arrarge the building with its long axis perpendicular to the wind. Clearly it cannot be arranged that this is always the case for the wind is continually changing direction, but the boiler house axis is chosen to be cerpendicular to the prevailing: wind in recognition of the above effect.

TABLE' 1 : BOILER HOUSE AND CHIMNEY HEIGHTS

\begin{tabular}{|l|cc|c|c|c|}
\hline Station & Size & Date & $\begin{array}{l}\text { Boiler } \\
\text { House } \\
\text { Height } \\
\mathrm{m}\end{array}$ & $\begin{array}{c}\text { Chimney } \\
\text { Height }\end{array}$ & $\begin{array}{c}\text { Ratio } \\
\text { of } \\
\text { Heights }\end{array}$ \\
\hline Taaibos & 480 & 1954 & 49 & 91 & 1,9 \\
Arnot & 2100 & 1971 & 74 & 195 & 2,6 \\
\hline
\end{tabular}




\section{DOWNWASH}

If the emission speed from the chimney is too low compared with the wind speed then the plume does not rise cleanly from the stack but, rather, dips slightly as it enters the atmosphere and does not fully recover, Figure (3). The plume becomes caught in the vortices shed by the chimney. If this downwash is very marked it can bring the plume down into the region of the downdraught from the boiler house and hence quickly to ground. To counter this the chimney should be as slender as possible in order that its vortices will be of small scale. Also, tests have shown that downwash can of ten be avoided if the emission speed is greater than the wind speed, a condition encouraged by a slender chimney. But if the chimney is made too slender then the pressure drop over its height becomes undesirably high and a considerable increase in fan power would be required. Moreover, too high an emission speed can be detrimental to plure rise because it can cause excessive entrainment of cold air from the general atmosphere thereby cooling the plume and reducing its buoyancy, Figure (3). A compromise is required and a typical emission speed nowadays is about $20 \mathrm{~m} / \mathrm{s}$ at full capacity, having been increasing over the years as incicated in Table 2. At less than full capacity the emission speed drops making downwash more likely and in recognition of this and other factors CEGB in UK now use multiflue chimneys as shown in Figure (4). With such a design the full capacity discharge is through all flues and wher the operation level reduces only one of the flues need bear a reduction in emissior speed. The flue openings are grouped very closely together in order that the separate discharges merge into one plume immediately after emission thus ersuring good plume rise due to the combined buoyancy. With this configuration wind tunnel tests showed that downwash was best avoided by terminating the chimney shell about $\frac{1}{3}$ of a diameter below the top of the flues. Multiflue chimneys do not feature in ESCON current planning because the load factors at their power stations are quite constant and the extra expense is not warranted.

\section{TABLE 2 : EMISSION SPEEDS}

\begin{tabular}{|l|c|c|c|c|}
\hline Station & Size & Date & $\begin{array}{c}\text { Chimney } \\
\text { Diameter } \\
\mathrm{m}\end{array}$ & $\begin{array}{c}\text { Emission } \\
\text { Speed } \\
\mathrm{m} / \mathrm{s}\end{array}$ \\
\hline Taaibos & 480 & 1954 & 5,4 & 15 \\
Arnot & 2100 & 1971 & 10,4 & 21 \\
\hline
\end{tabular}




\section{METEOROLOGICAL EF'FECTS}

Having ensured that the plume leaves the chimney in a suitable manner, its behaviour as it progresses away from the power station is next considered. It is common experience that wind speed influences the rise of a plume but there are two other meteorological conditions to consider as well, namely atmospheric turbulence and lapse rate. Turbulence refers to the small random fluctuations in wind speed which exist within the overall wind flow and which account for the spreading and mixing of the plume. It is generated by the passage of the wind over the earth's surface and also by vertical streams caused by the earth's surface heat. Lapse rate refers to the variation with height above ground of the temperature of the air. Fortunately, the two are interlinked to a considerable degree and categorising lapse rate is normally sufficient to give recognition to changes in turbulence levels also. In cases where differences in average turbulence level from one location to another are significant they can be catered for by a simple general appraisal as will be mentioned later.

A common lapse rate found during daytime is one with a temperature drop of about $I^{\circ} \mathrm{C}$ per 100 metres. This is the rate at which a pocket of gas would cool during expansion upon rising if mixing did not occur and therefore is commonly referred to as an adiabatic lapse rate and the atmosphere as neutral. In these circumstances the plume rises and disperses in a well behaved manner, called coning, as shown in Figure (5a). This is in distinct contrast to the plume behaviour when the lapse rate is superadiabatic as occurs when there is interse solar heating of the ground and hence of the air near the ground. The atmosphere is then unstable with much colder layers of air above and pockets of air continuously rise and fall giving a high level of turbulerce and resulting in a plume appearance as shown also in Figure (5b). This is known as looping and large variations occur in both vertical plane, as shown, and in the horizontal plane. A further distinctive lapse rate is the inversion lapse rate in which the air temperature increases with height giving a stable atmosphere with low turbulence. This commonly occurs at night when the earth's surface cools quite rapidly by radiation thus causing the air near the ground to cool as well. In these circumstances, as the plume rises and cocls it progresses into increasingly warmer air and therefore its buoyancy decreases 
with height ard its rise is supressed. It is called a fanning plume because its vertical spread is restricted, Figure (5c). However, the heights of chimneys at modern stations (around 150 to 200 metres) are such that they usually protrude through inversion layers and the plume rises quite normally. In view of this and recognising the very transient effects of a looping plume, the commonly occurring neutral conditions have received much attention by research workers and equations predicting plume rise in these conditions have been established. It has been found that if such equations are used in conjunction with a diffusion equation to calculate ground level concentrations of pollutants then such estimates give a good general indication of pollution severity for all conditions. However, confidence in the application of plume rise equations to South African conditions has first to be gained and ESCOM conducted experiments at two power stations for this purpose. The following: simple equation was found to be appropriate for tall chimneys: plume rise $\Delta h=\infty Q^{\frac{1}{4}} / U$ where $Q$ is the power in the stack gases, $U$ is the wind speed in the vicinity of the plume and

(the plume rise factor) is approximately a constant. This equation was first developed in the UK by CEGB and the study by ESCOM showed it to be suitable for the Highveld provided a slightly greater value of $C$ was used than in the UK. This is probably reflecting a lower average level of turbulence on the Highveld due to its flatness and freedom from extensive industrial and housing estates. Thus, al though turbulence does not appear explicitly in the equation it can be catered for in $\propto$ but changes in turbulence appear not to play a particularly dominant role.

The equation assumes that downdraught and downwash have been avoided and then the only plant parameter required is the power in the stack gases. This can be calculated from the furnace combustion design data and from estimates of heat losses in the ducting and dust collector, etc. The equation shows that at a modern 2000 MW Highveld power station with two chimney stacks $(Q=-150 \mathrm{NW})$ of 195 metres the plume rise in a high wind of say $10 \mathrm{~m} / \mathrm{s}$ would be a very significant 200 metres. The seeming wastage of energy in the hot combustion gases is now of distinct value in plume rise. The most dominant parameter in the equation is the wind speed at high level and for this reason good knowledge of wind speeds and directions should be known for any 
proposed site, particularly in densely populated areas.

\section{TOFOGRAPHICAL EFFECTS}

A further consideration in plume behaviour is the landscape of the ccuntryside surrounding the power station. Hills, ridges, lakes, or other prominent features can cause significant changes in the air 9 low pattern around power stations thereby affecting the path of the plume. For example, with a ridge downstream of the station, Figure (6a), if the chimney height is insufficier. ther the plume will be caught in the boundary layer over the ridge and brought to ground. But if the chimney is designed a little higher so as to avoid the boundary layer, which may extenc to a height of 30 metres above a 100 metre ridge for example, then the ridge may actually result in an uplifting of the plune. With an upwind ridge a significant depression of the plume can result as shown in Figure (6b). The wind coming off the ridge has a downward tendency for a considerable distance and can cause the plume rise to be lower than it otherwise would have been. For example, a 50 metre ridge at a distance of 1000 metres might cause a depression of 30 metres. In extreme cases the vortices from the ridge may actually bring the plume to ground near the station. Plume rise above a plain in a neutral atmosphere provides a basis from which to consider these influences of topography

Past experience of the above effects allows estimates of such influences to be made at the planning stage of new power stations but it is quite common for wind tunnel studies to be made for surety. Scale models of the countryside and the proposed power stations are made and by using a derise smoke in a helium/air mixture issuing from the chimney the plume behaviour can be quite readily observed. Also, on-site studies of wind patterns using flares dropped from aeroplanes are sometimes used. The gereral philosophy is to bring as much evidence as is reasonably possible to bear on the problem.

\section{$\underline{\text { CLOSURE }}$}

It has been shown how the behaviour of a plume in the atmosphere can be influenced by numerous effects, some of which are avoidable and others of which have to be accepted and accounted for. Even if downdraight and downwash are absent the plume behaviour remains complex but fortunately the 
somewhat more tractable and well studied case of a plume in a neutral atmosphere yields ultimate results of ground level concentrations which are quite generally applicable to other atmospheres. Equally, the plure rise in neutral conditions provides a basis from which to consider effects of to pos'raphy •

Considerable knowledge exists about the behaviour of plumes but environment standards are continually becoming stricter and therefore more detailed analyses of plume beraviour are constantly being sought.

\section{BIBLIOGRAPHY}

1. STERN, A.C. (Ed)

Air Pollution

Academic Press 1968.

2. SCOFER, R.S.

Air Pollution

Pergamon Press 1968.

3. NONHEBEL, G. (Ed)

Gas Purification Processes

Newnes-Butterworth, 2nd Edition, 1972.

4. STONE, G.N. \& CLARKE, A.J.

British Experience with Tall Stacks for Air Pollution Control on Large Fossil-Fueled Power Plants

Combustion, October 1967.

5. MAGLL, HOLDEN \& ACKLEY (Eds)

Air Pollution Handbook

McGraw-Hill 1956. 


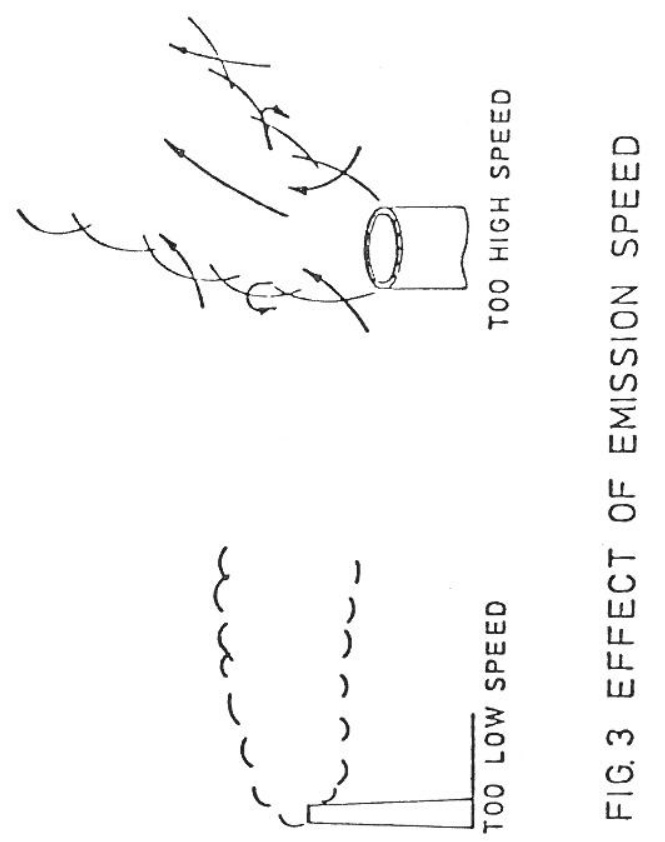

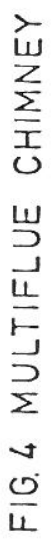
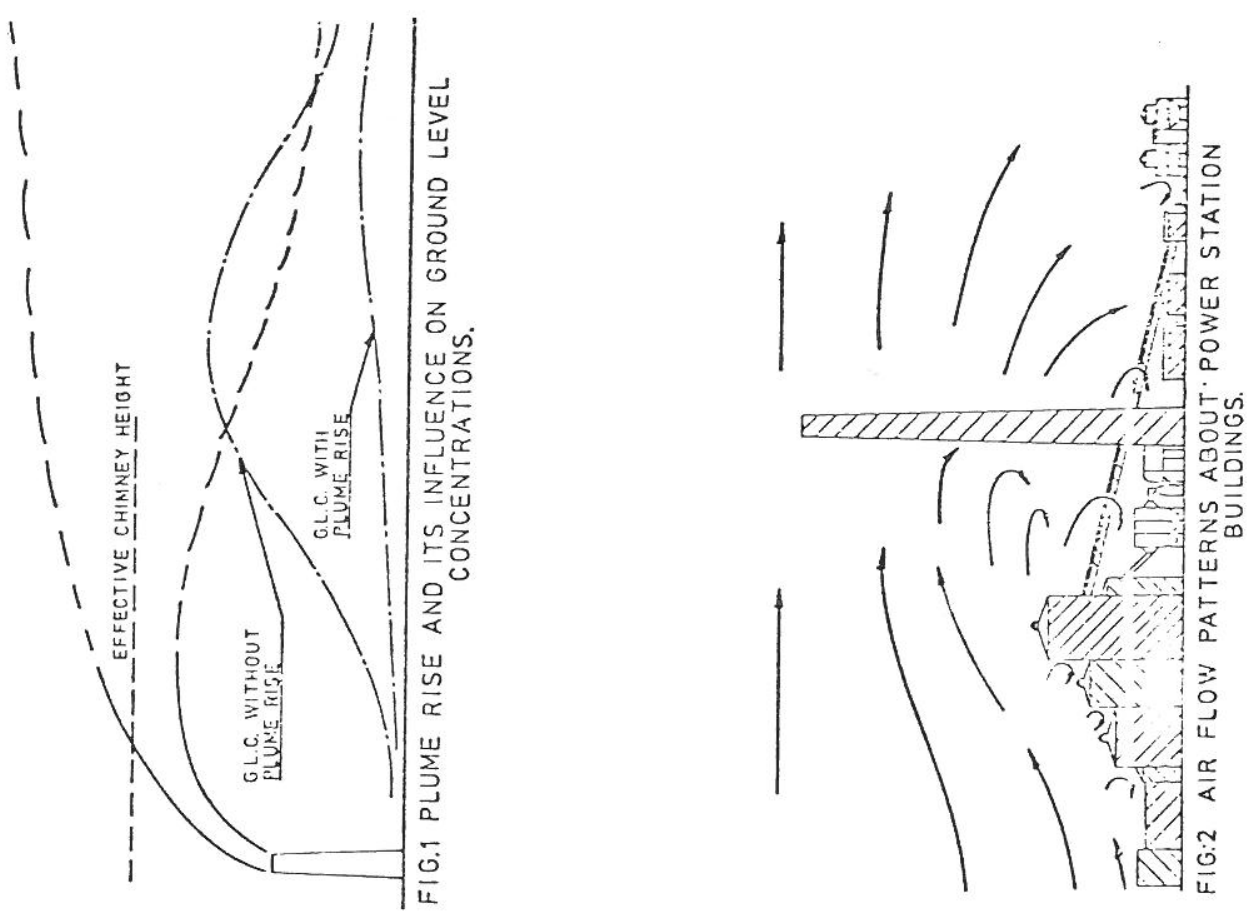

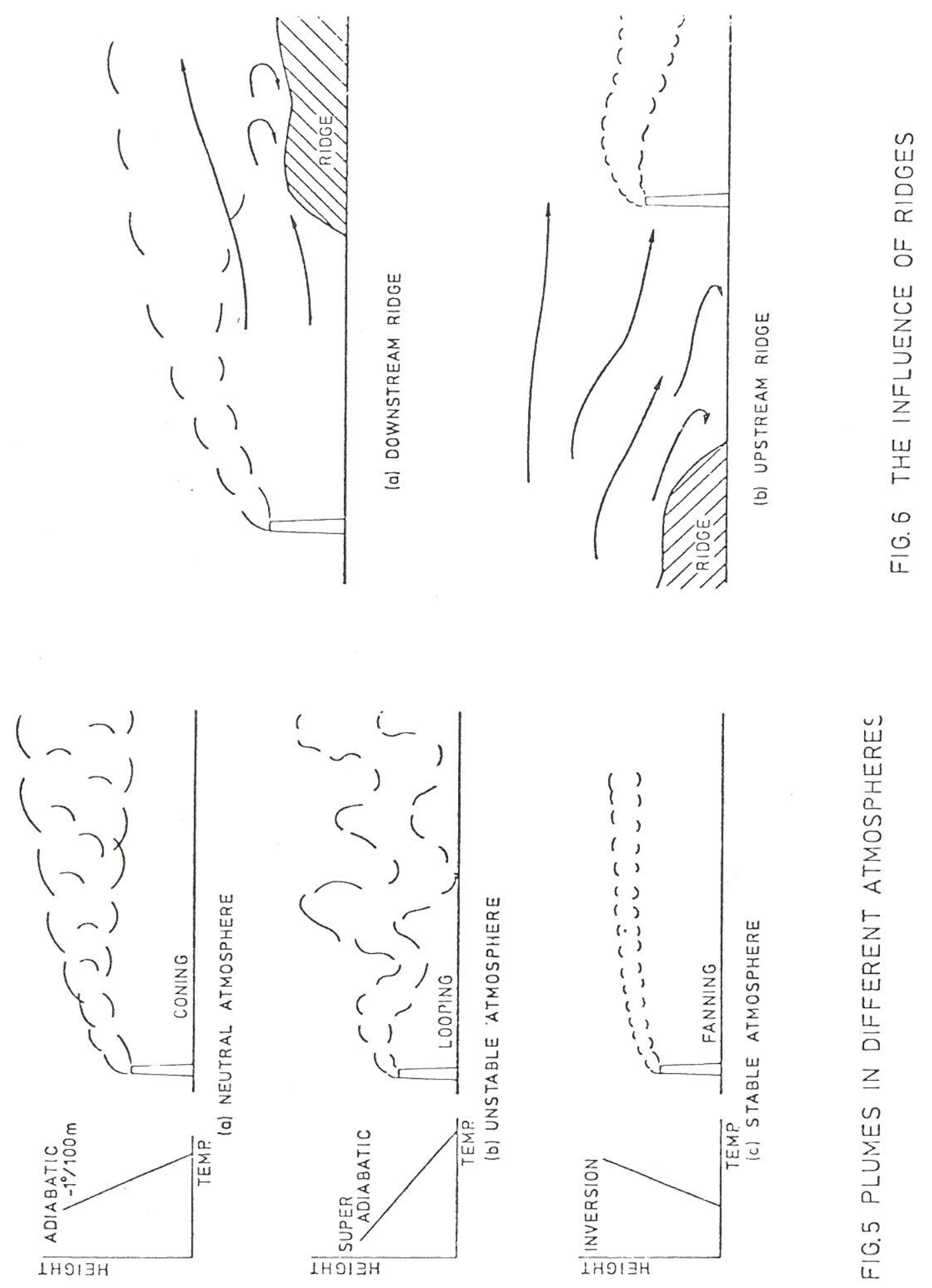